\title{
Do asymmetric risk metrics influence performance persistence?
}

\author{
Luis Ferruz , José Luis Sarto, and Laura Andreu \\ *Department of Accounting and Finance, Faculty of Economics and Business Studies, \\ University of Zaragoza, C/Gran Vía 2, 50005-Zaragoza, Spain. \\ Tel: + 34976 762494; Fax: + 34976 761791; E-mail: Iferruz@unizar.es
}

Received (in revised form): 4th March, 2008

\begin{abstract}
Luis Ferruz is Full Professor of Finance at the University of Zaragoza (Spain) and director of the research group GIECOFIN. He has published a large number of papers in journals such as Omega, Journal of Asset Management, Applied Economic Letters and Geneva Papers, and others. His research interests include portfolio management, performance persistence and style analysis in investment funds and corporate finance.
\end{abstract}

José Luis Sarto is Senior Lecturer at the University of Zaragoza. He has published a large number of papers in journals such as Omega, Journal of Asset Management, Applied Economic Letters and Applied Financial Economic Letters, and others. His research interests include behavioural finance and portfolio management.

Laura Andreu is Junior Lecturer at the University of Zaragoza. Her research interests include portfolio management, behavioural finance and pension funds performance. At the moment she is working on her PhD on the subject of the financial analysis of Spanish pension funds.

\section{Practical applications}

This paper is useful for investors and managers of money market funds since it tries to identify the true performance of these portfolios. The empirical results indicate incorrect performance valuations of Spanish funds when classical measures are considered. Two problems are detected: (1) asymmetric fund return distributions; (2) negative return premia. This latter feature is observed as the main reason that leads to the incoherent performance valuations. Hence, this paper provides the application of alternative performance measures to reach coherent performance rankings, very useful information for investors to evaluate the management of each fund and for fund managers to know their relative position in the market. Moreover, higher levels of performance persistence are found when alternative performance measures are applied, an interesting added value to investors when choosing a money market fund.

\section{Abstract}

This paper examines the influence of downside risk metrics when it comes to evaluating the performance persistence of Spanish money market funds. We present findings of important subsets of funds that show significant asymmetric return distributions; thus by taking alternative risk measures into account, such as semi-standard deviation and absolute deviation, we try to provide more appropriate performance rankings than those obtained with classic indices. We then adjust the performance indices used, given that significant subsets of funds with negative return premiums are found. The results provide strong evidence of markedly different rankings when considering adjusted
Journal of Derivatives \& Hedge Funds, Vol. 14 No. 1, 2008 , pp. 42-49 (C) 2008 Palgrave Macmillan Ltd $1753-9641 \$ 30.00$ 
performance measurements to avoid the effect of negative return premiums. Similar rankings, however, are achieved once the aforementioned effect is corrected, regardless of applying symmetric or asymmetric measures. Finally, a more accused empirical evidence of performance persistence using Cochran's test is observed in asymmetric measures, despite the similar classifications.

Journal of Derivatives \& Hedge Funds (2008) 14, 42-49. doi:10.1057/jdhf.2008.5

Keywords: asymmetric return distributions; money market funds; performance persistence

\section{INTRODUCTION AND AIMS}

The aim of this paper is to infer which measures are relevant in order to capture the performance of Spanish money market funds, given the presence of asymmetric return distributions and negative return premiums. It is also our aim to determine the influence of these measures on performance persistence.

The traditional risk measures used in finance are variance and standard deviation. However, it is a well-known fact in literature that these measures are not the most appropriate for evaluating the risk when returns are asymmetric. In these circumstances, authors like Sortino and Price, ${ }^{1}$ Eftekhari et al., ${ }^{2}$ Damant et al., ${ }^{3}$ Pedersen, ${ }^{4}$ Pedersen and Satchell, ${ }^{5,6}$ Hwang and Pedersen, ${ }^{7}$ defend the use of other indicators such as absolute deviation, semi-standard deviation and semi-variance, among others.

Eftekhari et al. ${ }^{2}$ conclude that the standard deviation may be the appropriate risk measure for high volume markets like Germany, the UK and France, but it is not the most reliable risk measure when considering lower volume markets like Italy, Holland and Belgium.
Recent studies that focus on the application of asymmetric risk measures are those conducted by Hyung and De Vries, ${ }^{8}$ who compare the benefits of portfolio diversification for downside risk in case returns that are normally distributed with the case fat-tailed distributed returns, and Campbell and Kraeussl, ${ }^{9}$ who observe the international equity allocation for the downside risk investor.

Other recent studies have been carried out by Cheng $^{10}$ and Morton et al. ${ }^{11}$ Cheng $^{10}$ presents us six asymmetric risk metrics to test their ability to explain the cross-sectional variations in real estate returns, and Morton et al. ${ }^{11}$ state that skewness and larger kurtosis are observed in monthly return series of hedge funds, which leads to underestimation of volatility and, as a result, overestimation of Sharpe's ratio if it is used as a performance measure.

Owing to the asymmetric return distributions, this paper examines the annual performance rankings, obtained by applying Sharpe's ratio, ${ }^{12}$ by considering a traditional risk measure such as standard deviation, and some downside risk measures (absolutedeviation and semi-standard deviation) to detect whether important differences exist in the rankings and to assess the influence of applying the different metrics on the persistence phenomenon.

Negative return premiums, by comparing portfolio return with risk-free assets (Treasury Repos with overnight securities), are also detected in the vast majority of the money market funds analysed. This problem is also shown in Ferruz et al. ${ }^{13}$ when analysing the Spanish equity fund industry; so, we follow the same complementary approach in this study, previously proposed by Ferruz et al. ${ }^{14}$ and Ferruz and Sarto. ${ }^{15,16}$

The two aims tackled in this paper are original, and little research has been carried out 
on them in relation to Spanish money market funds. Above all, the influence of asymmetric risk measures on performance persistence is an issue that has not been closely looked at in financial literature, as far as we know.

Some interesting results are found when the correlation between all the applied performance indices is analysed. Significantly different rankings are obtained when metrics that correct the effect of negative return premium, and likewise when those that do not correct this effect, are applied. Similar rankings, however, are found when downside risk metrics and standard deviation are applied, showing that the important issue is the consideration of relative premiums.

Finally, greater annual performance persistence is found when asymmetric risk measurements are applied, as Cochran's test suggests.

The remainder of the paper is organised as follows: the next section describes the Spanish fund industry and data used; the subsequent section contains the description of the different performance measures analysed; the penultimate section focuses on the persistence phenomenon when different risk metrics are applied; finally, the last section contains concluding remarks.

\section{INDUSTRY AND DATA}

The Spanish fund industry has caught up with the US development of investment funds as a vehicle of investment from the 1990s. The recent growth of the asset under management by Spanish funds has been one of the biggest in Europe over the past 15 years, with a compounded annual growth rate of more than 25 per cent.

In 2004 almost $€ 220$ billion have been managed by approximately 2,600 Spanish investment funds, which is 26.1 per cent of the GDP. In terms of asset under management, Spain is ranked in sixth place in the European Union (EU), just behind Luxembourg, France, United Kingdom, Ireland and Italy, respectively. The average assets managed by each fund, however, are still among the lowest in the EU, thereby pointing out an industry where a small number of large funds coexist with mainly small funds.

As part of the investment fund industry, money market funds are an important category, managing more than $€ 56$ billion and representing more than 25 per cent of total assets in the fund industry, a significantly higher percentage than those obtained in other developed fund industries such as the US (approximately 5 per cent), which affirms the interest in conducting research into Spanish money market funds.

The data set includes the daily return of all Spanish money market funds and of Treasury Repos with overnight securities (risk-free asset) from January 1995 to December 2004. This ten-year period is of paramount importance because it is the period in which the industry really developed.

The information provided by the Spanish Securities and Exchange Commission (CNMV) allows us to create a survivor bias-free data set. Therefore, the existing asymmetry is not understated. The skewness coefficient of Fisher is used to assess the existence of this phenomenon in the data.

$$
a_{3}=\frac{\left(\sum_{t=1}^{n} R_{t}-E(R)\right)^{3} / n}{\sigma^{3}}
$$

On the other hand, the vast majority of the funds show negative return premiums compared to the risk-free assets for all time periods except the first. In this situation, Ferruz et al. ${ }^{14}$ and Ferruz and Sarto ${ }^{15,16}$ demonstrate that Sharpe's ratio does not function properly because the partial derivative for the level of risk in the portfolio is positive. 
Table 1: Summary of statistics of the money market fund sample

\begin{tabular}{llll}
\hline & $\begin{array}{l}\text { Number } \\
\text { of funds }\end{array}$ & $\begin{array}{l}\text { Funds with } \\
\text { negative return } \\
\text { premium }\end{array}$ & $\begin{array}{l}\text { Funds with } \\
\text { asymmetric } \\
\text { returns }^{\mathrm{a}}\end{array}$ \\
\hline 1995 & 135 & 1 & 131 \\
1996 & 152 & 149 & 146 \\
1997 & 179 & 175 & 163 \\
1998 & 201 & 198 & 192 \\
1999 & 199 & 197 & 156 \\
2000 & 197 & 191 & 170 \\
2001 & 170 & 167 & 139 \\
2002 & 159 & 157 & 106 \\
2003 & 157 & 152 & 136 \\
2004 & 163 & 159 & 141 \\
\hline
\end{tabular}

${ }^{\mathrm{a}}$ These returns are asymmetric at 5 per cent.

The first two columns of the table show the different annual periods analysed and the total number of funds examined, whereas the following two columns contain the number of funds with negative return premium and asymmetry problems, respectively.

Therefore, the aforementioned authors suggest an alternative performance measure to Sharpe's ratio, which, while maintaining the nature of the original index, considers the return premium in relative terms.

$$
S_{p}(1)=\frac{E_{p} / R_{f}}{\sigma_{p}}
$$

where $E_{p}$ represents the average return on portfolio $p ; R_{f}$ indicates the average return on the risk-free asset; $\sigma_{p}$ is the standard deviation of the return on portfolio $p$.

This alternative measure provides consistent rankings for any set of funds with the only requirement that $E_{p}>0$ for all portfolios. This metric overcomes the inconsistencies observed in the original ratio proposed by Sharpe ${ }^{17}$; however, it does not show significantly different rankings when portfolios display similar levels of risk. Consequently, the $S_{p}(1)$ ratio is considered an appropriate performance measurement in this case.

Table 1 gathers a summary of the statistics of the investment funds analysed. As can be seen, a larger number of Spanish money market funds show both problems: asymmetry in the return distributions and negative return premiums.

This asymmetry problem in the Spanish market, as Ferruz et al..$^{13}$ point out, could be due to the youth of the market because the investment funds have only experienced high growth in the last 15 years, which is a short period of time compared to more mature markets like the US or UK.

\section{PERFORMANCE MEASURES}

The first performance metric applied is Sharpe's ratio, which considers the standard deviation as measure of risk. Then, due to the negative return premiums, $S_{p}(1)$ is calculated, which implies a modification from absolute premiums to relative premiums. Finally, two alternative indices are carried out in order to take downside risk metrics into account.

These two alternative indices are expressed as follows:

$$
P(1)=\frac{E_{p} / R_{f}}{S S D_{p}}
$$

where $E_{p}$ represents the average return on portfolio $p ; R_{f}$ indicates the average return on the risk-free asset; $S S D_{p}$ is the semi-standard deviation of the return on portfolio $p$.

$$
S S D p=\left[\frac{1}{n} \sum_{t=1}^{n}\left(\min \left[0, R_{p t}-E_{p}\right]\right)^{2}\right]^{1 / 2}
$$

This index is therefore similar to Sortino's index, although the return premium is expressed in 
Table 2: Correlation coefficients amongst the performance measures

\begin{tabular}{lllll}
\hline & Sharpe & $S_{p}(1)$ & $P(1)$ & $P(2)$ \\
\hline Sharpe & - & 0.0317 & 0.0270 & 0.0359 \\
$S_{p}(1)$ & - & - & 0.9590 & 0.9736 \\
$P(1)$ & - & - & - & 0.9239 \\
$P(2)$ & - & - & - & - \\
\hline
\end{tabular}

relative terms.

$$
P(2)=\frac{E_{p} / R_{f}}{A D_{p}}
$$

where $A D_{p}$ indicates the absolute deviation of the returns on portfolio $p$, which would be calculated as follows:

$$
A D_{p}=E\left[\left|R_{p}-E_{p}\right|\right]
$$

Once the different performance measures are calculated, we analyse the levels of correlation among them in order to detect whether the annual rankings provided are similar or otherwise very different. These results are shown in Table 2.We can observe some important results in Table 2. On the one hand, very little correlation is observed between Sharpe's ratio and the others, indicating that considering relative premiums very different performance rankings are found.On the other hand, the high correlation between $S_{p}(1), P(1)$ and $P(2)$ indicates that no material changes in performance rankings exist. Thus, there is no reason to change from traditional risk measures to asymmetric measures.

\section{PERFORMANCE PERSISTENCE USING DIFFERENT RISK METRICS}

Finally, in order to improve knowledge of the importance of measuring the risk with different metrics, an additional and novel analysis has been carried out.

Little research has been done on the influence of asymmetric risk metrics on performance persistence, in spite of its importance; this paper tries to fill this void.

The persistence study has been carried out by applying a non-parametric methodology in the three measures that provide similar performance rankings. ${ }^{18}$

In this analysis, $2 \times 2$ contingency tables are defined by comparing performance rankings in two consecutive investment periods. Thus, two categories are determined in each period:

Winner and Loser funds, depending on whether the funds have higher or lower returns than the median.

So, $W W(L L)$ denotes the number of funds that are winners (or losers) in two consecutive periods, whereas $W L(L W)$ represents the number of funds that are winners (or losers) in the first period, then losers (or winners) in the consecutive performance ranking.

Once the different subsets of funds have been determined, the statistical significance of persistence can be obtained using the $Z$-test, the Odds Ratio, the Chi-square test and Cochran's test.

- The $Z$-test for repeat winners applied by Malkiel $^{19}$ :

$$
Z=\frac{Y-n p}{\sqrt{n p(1-p)}} Z \approx N(0,1)
$$

where $Y$ is the number of winner funds in two consecutive periods; $n$ is the total number of winner funds in the first period; $p$ is the probability that a winner fund repeats as a winner in the following period. Using the median 
Table 3: Performance persistence results

\begin{tabular}{|c|c|c|c|c|c|c|c|c|}
\hline & $W W$ & $L L$ & $L W$ & $W L$ & Malkiel Z-test & $B \mathcal{E} G Z$-test & 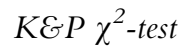 & Cochran Y-test \\
\hline \multicolumn{9}{|l|}{ Panel $A$} \\
\hline 1995-1996 & 54 & 53 & 14 & 14 & $4.851 \star \star$ & $6.315^{\star \star}$ & $46.244 \star \star$ & \\
\hline 1996-1997 & 54 & 53 & 22 & 22 & $3.671 \star \star$ & $4.962 \star \star$ & $26.298 \star \star$ & \\
\hline 1997-1998 & 63 & 62 & 26 & 26 & $3.922 \star \star$ & $5.315^{\star \star}$ & $30.119 \star \star$ & \\
\hline 1998-1999 & 68 & 67 & 30 & 30 & $3.839 \star \star$ & $5.226 \star \star$ & $28.856^{\star \star}$ & \\
\hline 1999-2000 & 77 & 77 & 19 & 19 & $5.920 \star \star$ & $7.726 \star \star$ & $70.083 \star \star$ & $16.739 \star \star$ \\
\hline 2000-2001 & 58 & 57 & 26 & 26 & $3.491 \star \star$ & $4.749 \star \star$ & $23.778^{\star \star}$ & \\
\hline $2001-2002$ & 51 & 51 & 28 & 28 & $2.588 \star \star$ & $3.605 \star \star$ & $13.392 \star \star$ & \\
\hline 2002-2003 & 51 & 50 & 26 & 26 & $2.849 \star \star$ & $3.889 \star \star$ & $15.706 \star \star$ & \\
\hline 2003-2004 & 58 & 58 & 18 & 18 & $4.588 \star \star$ & $6.133 \star \star$ & $42.105^{\star \star}$ & \\
\hline \multicolumn{9}{|l|}{ Panel B } \\
\hline 1995-1996 & 53 & 52 & 15 & 15 & $4.608 \star \star$ & $6.051 \star \star$ & $41.681^{\star \star}$ & \\
\hline 1996-1997 & 57 & 56 & 19 & 19 & $4.359 \star \star$ & $5.811^{\star \star}$ & $37.265^{\star \star}$ & \\
\hline 1997-1998 & 62 & 61 & 27 & 27 & $3.710^{\star \star}$ & $5.043 \star \star$ & $26.910 \star \star$ & \\
\hline 1998-1999 & 67 & 66 & 31 & 31 & $3.637 \star \star$ & $4.963 \star \star$ & $25.862^{\star \star}$ & \\
\hline 1999-2000 & 78 & 78 & 18 & 18 & $6.124 \star \star$ & $7.930 \star \star$ & $75.000 \star \star$ & $17.675 \star \star$ \\
\hline $2000-2001$ & 62 & 61 & 22 & 22 & $4.364 \star \star$ & $5.852 \star \star$ & $37.383 \star \star$ & \\
\hline 2001-2002 & 53 & 53 & 26 & 26 & $3.038 \star \star$ & $4.207 \star \star$ & $18.456 \star \star$ & \\
\hline 2002-2003 & 52 & 51 & 25 & 25 & $3.077 \star \star$ & $4.193 \star \star$ & $18.373 \star \star$ & \\
\hline 2003-2004 & 59 & 59 & 17 & 17 & $4.818 \star \star$ & $6.393 \star \star$ & $46.421 \star \star$ & \\
\hline \multicolumn{9}{|l|}{ Panel C } \\
\hline 1995-1996 & 55 & 54 & 13 & 13 & $5.093 \star \star$ & $6.567 \star \star$ & $51.044 \star \star$ & \\
\hline 1996-1997 & 55 & 54 & 21 & 21 & $3.900 \star \star$ & $5.251 \star \star$ & $29.742^{\star \star}$ & \\
\hline 1997-1998 & 67 & 66 & 22 & 22 & $4.770 \star \star$ & $6.360 \star \star$ & $44.763 \star \star$ & \\
\hline 1998-1999 & 67 & 66 & 31 & 31 & $3.637 \star \star$ & $4.963 \star \star$ & $25.862 \star \star$ & \\
\hline 1999-2000 & 76 & 76 & 20 & 20 & $5.715 \star \star$ & $7.512^{\star \star}$ & $65.333 \star \star$ & $18.819 \star \star$ \\
\hline $2000-2001$ & 66 & 65 & 18 & 18 & $5.237 \star \star$ & $6.864 \star \star$ & $54.054 \star \star$ & \\
\hline 2001-2002 & 54 & 54 & 25 & 25 & $3.263 \star \star$ & $4.502^{\star \star}$ & $21.291 \star \star$ & \\
\hline $2002-2003$ & 57 & 56 & 20 & 20 & $4.217 \star \star$ & $5.644 \star \star$ & $34.843 \star \star$ & \\
\hline 2003-2004 & 57 & 57 & 19 & 19 & $4.359 \star \star$ & $5.865^{\star \star}$ & $38.000 \star \star$ & \\
\hline
\end{tabular}

$\star \star$ Persistence statistically significant at 1 per cent.

This table is divided into three panels: the information provided in panel A relates to $S_{p}(1)$, the information in panel $\mathrm{B}$ refers to $P(1)$ and the information in panel $\mathrm{C}$ relates to $P(2)$. The first column of the table shows the consecutive annual periods analysed. The next four columns show the $2 \times 2$ contingency tables obtained, and the last four columns present the results of the statistical tests explained above. 
criterion and supposing there is no relationship between the two periods, $p$ would be 0.5 .

- The Odds Ratio (OR) applied by Brown and Goetzmann ${ }^{20}$ :

$$
O R=\frac{W W * L L}{W L * L W}
$$

This equation is the ratio of funds that display persistence to those that do not. Using the median criterion, if the ratio is equal to one, it implies that each category has a quarter of the total number of funds and there is no persistence.

Based on this ratio a $Z$-test is calculated.

$$
Z=\frac{\ln (O R)}{\sigma_{\log (O R)}} \quad Z \approx N(0,1)
$$

- The $\chi 2$-statistic applied by Kahn and

$$
\begin{aligned}
& \operatorname{Rudd}^{21,22}: \\
& \quad \chi^{2}=\sum_{i=1}^{n} \sum_{j=1}^{n} \frac{\left(O_{i j}-E_{i j}\right)^{2}}{E_{i j}} \chi^{2} \approx \chi^{2}(r-1)(c-1)
\end{aligned}
$$

where $O_{i j}\left(E_{i j}\right)$ is the actual (expected) frequency in the $i$ th row and the $j$ th column in the table; $r$ (c) is the number of rows (columns) in the contingency table.

The above equations determine performance persistence by considering consecutive periods. To confirm whether this fact exists for the whole period analysed, Cochran's test (1954) has been applied. As far as we know, this is one of the first studies to apply this approach.

- Cochran's test ${ }^{23}$ :

$$
Y=\frac{\sum_{i=1}^{g} w_{i} d_{i}}{\left(\sum_{i=1}^{g} w_{i} P_{i} Q_{i}\right)^{1 / 2}} Y \approx N(0,1)
$$

where

$$
P_{i}=\frac{n_{i 1} p_{i 1}+n_{i 2} p_{i 2}}{\left(n_{i 1}+n_{i 2}\right)}
$$

$$
\begin{gathered}
Q_{i}=\left(1-P_{i}\right) \\
d_{i}=\left(p_{i 1}-p_{i 2}\right)
\end{gathered}
$$

$$
w_{i}=\frac{n_{i 1} n_{i 2}}{\left(n_{i 1}+n_{i 2}\right)}
$$

$n_{i 1}\left(n_{i 2}\right)$ is $W W+W L(L L+L W)$ in each contingency table, $p_{i 1}\left(p_{i 2}\right)$ is the relationship between $W W(L W)$ and $n_{i 1}\left(n_{i 2}\right)$ and $g$ is the number of $2 \times 2$ tables analysed.

The results of this analysis are shown in Table 3, in which a significant persistence in the three performance measures can be observed. No considerable difference is observed when paying attention to one-period tests; however, when we focus on Cochran's test, we can see that asymmetric risk measures tend to magnify the persistence phenomenon, although this effect is not exacerbated.

\section{CONCLUDING REMARKS}

This section presents the conclusions of analysing the best way to capture the performance of Spanish money market funds and persistence phenomenon by applying different measures over a ten-year period: 19952004.

The negative return premiums (the average return corresponding to risk-free assets is not attained by an important subset of funds) and the asymmetric return distributions lead us to 
question which performance metrics are the most appropriate.

The results show that the key issue is to correct the negative return premiums and consider them in relative terms. Once this has been done, the application of traditional or downside risk measures do not provoke very different performance rankings.

Finally, a stronger persistence phenomenon is observed in Cochran's test for the whole time period when asymmetric measures are applied, although the differences are confined.

\section{Acknowledgments}

The authors would like to express their thanks to the University of Zaragoza for the award of projects 268-128, 268-147 and 268-159 and to the Ministry of Education for the award of project SEJ 2006-04 208 with European FEDER funds. Any possible errors are the exclusive responsibility of the authors.

\section{References and Notes}

1 Sortino, F.A. and Price, L.N. (1994) 'Performance Measurement in a Downside Risk Framework', Journal of Investing, Fall, pp. 59-72.

2 Eftekhari, B., Pedersen, C.S. and Satchell, S.E. (2000) 'On the Volatility of Measures of Financial Risk: An Investigation Using Returns from European Markets', The European Journal of Finance, Vol. 6, pp. 18-38.

3 Damant, D., Hwang, S. and Satchell, S. (2000) 'Using a Model of Integrated Risk to Assess UK Asset Allocation', Applied Mathematical Finance, Vol. 7, No. 2, pp. 127-152.

4 Pedersen, C. (2001) 'Derivatives and Downside Risk', Derivatives Use, Trading and Regulation, Vol. 7, No. 3, pp. 251-268.

5 Pedersen, C. and Satchell, S. (2000) 'Small Sample Analysis of Performance Measures in the Asymmetric Response Model', Journal of Financial and Quantitative Analysis, Vol. 35, No. 3, pp. 425-450.

6 Pedersen, C.S. and Satchell, S.E. (2002) 'On the Foundations of Performance Measures Under Asymmetric Returns', Quantitative Finance, Vol. 3, pp. 217-223.

7 Hwang, S. and Pedersen, C. (2002) 'On Empirical Risk Measurement with Asymmetric Return Distributions', Financial Econometrics Research Centre Working
Paper WP02-07, City University Business School, London.

8 Hyung, N. and De Vries, C.G. (2005) 'Portfolio Diversification Effects of Downside Risk', Journal of Financial Econometrics, Vol. 3, No. 1, pp. 107-125.

9 Campbell, R. and Kraeussl, R. (2007) 'Revisiting the Home Bias Puzzle: Downside Equity Risk', Journal of International Money and Finance, Vol. 26, No. 7, pp. $1239-1260$.

10 Cheng, P. (2005) 'Asymmetric Risk Measures and Real Estate Returns', Journal of Real Estate Finance and Economics, Vol. 30, No. 1, pp. 89-102.

11 Morton, D., Popova, I. and Popova, E. (2006) 'Efficient Fund of Hedge Funds Construction under Downside Risk Measures', Journal of Banking and Finance, Vol. 30, No. 2, pp. 503-518.

12 Only Sharpe's ratio is applied because the investment funds analysed are money market funds. Treynor's ratio and Jensen's alpha do not make sense in these funds.

13 Ferruz, L., Pedersen, C. and Sarto, J.L. (2006) 'Performance Metrics for Spanish Investment Funds', Derivatives, Use, Trading and Regulation, Vol. 12, No. 3, pp. 219-227.

14 Ferruz, L., Sarto, J.L. and Vargas, M. (2003) 'Analysis of Performance Persistence in Spanish Short-Term Fixed Interest Investment Funds (1994-2002)', European Review of Economics and Finance, Vol. 2, No. 3, pp. 61-75.

15 Ferruz, L. and Sarto, J.L. (2004) 'An Analysis of Spanish Investment Funds Performance: Some Considerations Concerning Sharpe's Ratio', Omega, The International Journal of Management Science, Vol. 32, pp. 273-284.

16 Ferruz, L. and Sarto, J.L. (2005) 'Some Reflections on the Sharpe Ratio and its Empirical Application to Fund Management in Spain', Advances in Investment Analysis and Portfolio Management, Vol. I, pp. 205-224.

17 Sharpe, W.F. (1966) 'Mutual Fund Performance', Journal of Business, Vol. 39, pp. 119-138.

$18 S_{p}(1), P(1)$ and $P(2)$.

19 Malkiel, B. (1995) 'Returns from Investing in Equity Mutual Funds 1971 to 1991', Journal of Finance, Vol. 50, pp. 549-572.

20 Brown, S.J. and Goetzmann, W.N. (1995) 'Performance Persistence', Journal of Finance, Vol. 50, pp. 679-698.

21 Kahn, R.N. and Rudd, A. (1995) 'Does Historical Performance Predict Future Performance?', Financial Analysts Journal, Vol. 51, pp. 43-52.

22 This distribution presents one degree of freedom in $2 \times 2$ contingency tables analysis.

23 Cochran, W.G. (1954) 'Some Methods for Strengthening the Common $\chi^{2}$ Tests', Biometrics, Vol. 10, pp. 417-451. 